\title{
Preliminary analysis of different microRNA expression levels in juvenile angiofibromas
}

\author{
CORNELIA LERNER, SILKE WEMMERT and BERNHARD SCHICK \\ Department of Otolaryngology, Saarland University Medical Center, D-66421 Homburg/Saar, Germany
}

Received June 12, 2014; Accepted July 22, 2014

DOI: $10.3892 /$ br. 2014.350

\begin{abstract}
Juvenile angiofibroma (JA) is a rare fibrovascular tumor affecting, almost exclusively, adolescent males. The finding of frequent $\beta$-catenin-mutations in JAs emphasized the significance of the Wnt-signaling pathway in tumor pathogenesis. In the last decade, microRNAs (miRNAs or miRs) have been found to be involved in cancer pathogenesis by post-transcriptional regulation of gene expression and have not been analyzed in JAs thus far. In the present study, the expression of 4 miRNAs (hsa-let-7d, hsa-miR-98, hsa-miR-125a-5p and hsa-miR-218) was analyzed in 13 JAs and 3 deepithelized inferior nasal turbinates that were used as control tissue. The miRNA expression of hsa-let-7d $(\mathrm{P}=0.158)$ and hsa-miR-98 $(\mathrm{P}=0.069)$ was not statistically different between the two tissue types, however, a significant decrease in expression was observed for hsa-miR-125a-5p ( $\mathrm{P}=0.037)$ and hsa-miR-218 $(\mathrm{P}=0.009)$ in JAs compared to inferior nasal turbinates. As downregulation of miRNA 218 has been recently shown to result in stabilization and nuclear accumulation of $\beta$-catenin, the present data indicates further evidence for the importance of the Wnt-signaling pathway in JAs.
\end{abstract}

\section{Introduction}

Juvenile angiofibroma (JA) is a unique fibrovascular tumor that affects adolescent males almost exclusively. Tumor origin has been depicted close to the pterygoid base and sphenopalatine foramen. Branches of the external carotid artery (mainly maxillary/sphenopalatine artery) and also the internal carotid artery can support this highly vascularized tumor. Despite having a benign nature, JAs may show an aggressive growth pattern with bone destruction. In contrast to these well-known clinical tumor characteristics (1), tumor biology has only recently started to be elucidated.

Correspondence to: Dr Silke Wemmert, Department of Otolaryngology, Saarland University Medical Center, 6 Kirrberger Strasse, D-66421 Homburg/Saar, Germany

E-mail: silke.wemmert@uks.eu

Key words: juvenile angiofibroma, microRNA, Wnt-pathway, $\beta$-catenin
In recent years, microRNAs (miRNAs or miRs), which are small molecules of $\leq 20-23$ nucleotides, have been shown to be involved in post-transcriptional regulation of gene expression and are therefore the focus for tumor pathogenesis, as cancer diagnostic markers and in anticancer therapy (2). Numerous miRNAs have been found to be up or downregulated, not only in various tumors, such as head and neck squamous cell carcinomas (HNSCC) (3), but are also associated with chronic rhinosinusitis and allergic rhinitis (4).

The altered function of the Wnt- $\beta$-catenin-signaling pathway components is associated with a variety of types of cancer. In the absence of Wnt, glycogen synthase kinase (GSK)-3 $\beta$ collaborates with other factors to phosphorylate $\beta$-catenin, preventing its nuclear accumulation and leading to ubiquitination and degradation of $\beta$-catenin. Notably, this has occurred in $\leq 75 \%$ of analyzed JA $\beta$-catenin-mutations observed, which are known to result in stabilization and nuclear accumulation of $\beta$-catenin (5). A highly noteworthy finding in this context is the affect of miRNA 218 on the Wnt-signaling pathway. Via inhibition of Akt (6), miRNA 218 can induce the inhibition of GSK-3 $\beta$, resulting in $\beta$-catenin stabilization. To the best of our knowledge, this is the first study that aimed to analyze miRNA deregulation of 4 different miRNAs with regards to $\beta$-catenin signaling in JA.

\section{Materials and methods}

Patients. Tumor samples from 13 male angiofibroma patients (median, 15 years) were examined. Approval for the study was obtained from the Local Ethics Committee. Tumor diagnosis was confirmed by detailed histopathological evaluation, as described previously (7). At the time of tumor sample collection, one patient was at tumor grade I and 12 were tumor grade III. The tissue from the inferior nasal turbinates was available from inferior turbinate surgery for treatment of nasal obstruction in otherwise healthy individuals and served as control tissue. The tissue samples were snap-frozen in liquid nitrogen in the laboratory within minutes of collection. Prior to surgery, all the patients were informed and provided written consent for donating tissue for research purposes.

miRNA isolation. For miRNA expression analysis, the superficial epithelial layer of the nasal turbinates was removed in order to obtain homogenous stromal tissue samples beside the tumor probes. All the frozen tissue samples were homogenized 

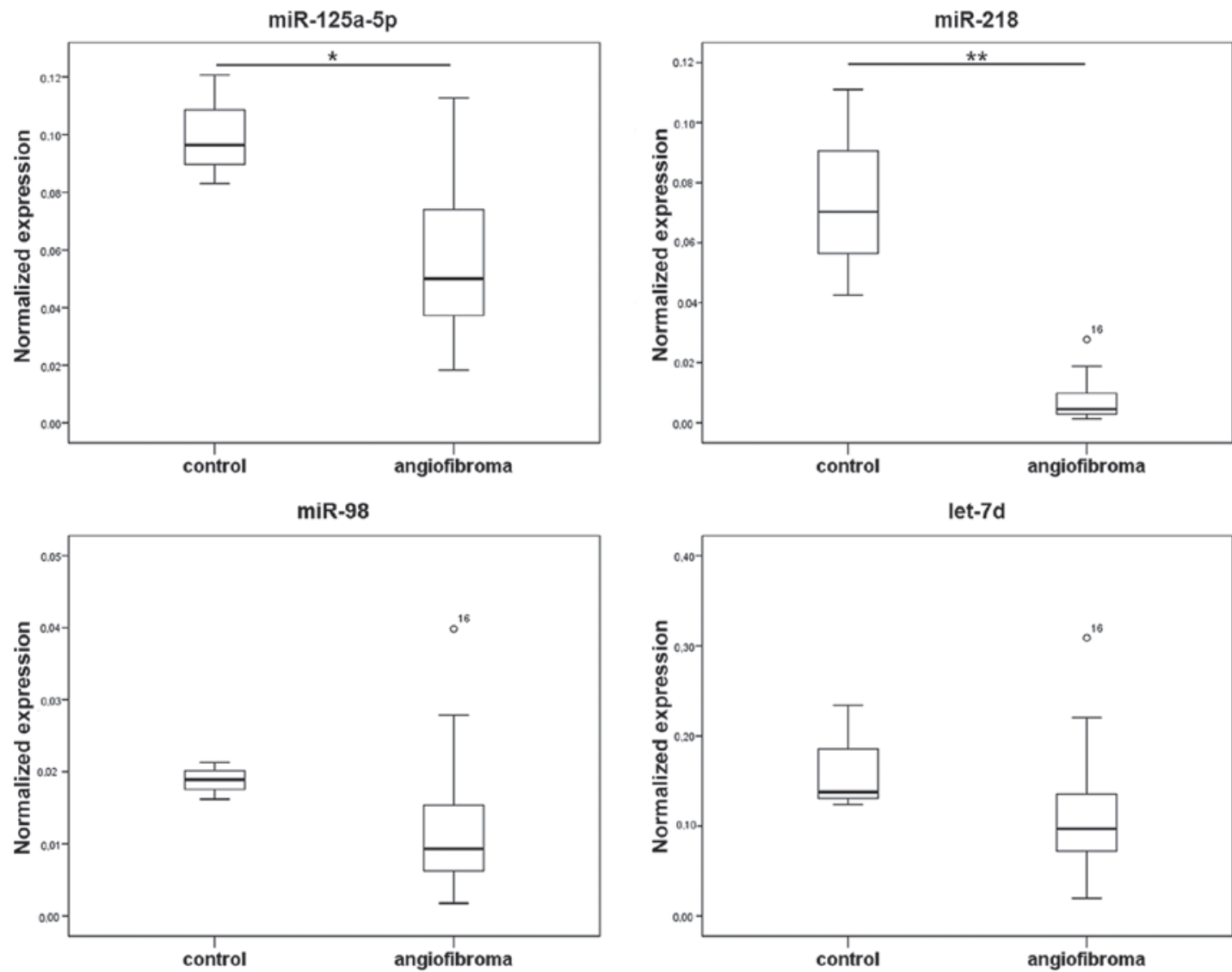

Figure 1. Normalized expression of analyzed microRNAs (miRNAs or miRs). Boxplots of miR-125a-5p, miR-218, miR-98, let-7d in subepithelial inferior turbinate tissue $(n=3)$ served as controls and angiofibroma tissue $(n=13)$ derived from reverse transcription-quantitative polymerase chain reaction are shown. The expression results were considered to indicate a statistically significant difference when $\mathrm{P}<0.05\left({ }^{*} \mathrm{P}<0.05 ;{ }^{* * *} \mathrm{P}<0.01\right)$ using Mann-Whitney $\mathrm{U}$ test. Angiofibroma grade I represents the statistical outlier $\left(\mathrm{O}^{16}\right)$ compared to the angiofibroma grade III $(\mathrm{n}=12)$.

and total RNA, including miRNA, was isolated using the miRNeasy Mini kit (Qiagen, Hilden, Germany) according to the manufacturer's instructions. RNA was quantified using a NanoDrop ${ }^{\mathrm{TM}}$ Spectrophotometer ND-1000 (Peqlab Biotechnologie $\mathrm{GmbH}$, Erlangen, Germany) and stored at $-20^{\circ} \mathrm{C}$ until required.

Reverse transcription quantitative polymerase chain reaction $(R T-q P C R)$. The expression of 4 miRNAs was analyzed using RT-qPCR and TaqMan ${ }^{\circledR}$ miRNA assays (Applied Biosystems Inc., Foster City, CA, USA). For hsa-let-7d, hsa-miR-98, hsa-miR-125a-5p and hsa-miR-218 miRNA and the endogenous control, RNU48, a total of $100 \mathrm{ng}$ RNA was converted into cDNA using the TaqMan ${ }^{\circledR}$ MicroRNA Reverse Transcription kit (Applied Biosystems Inc.) according to the manufacturer's instructions. qPCR was performed with the TaqMan ${ }^{\circledR}$ Gene Expression Master mix (Applied Biosystems Inc.) in a total volume of $10 \mu \mathrm{l}$ per reaction containing $1 \mu 1$ cDNA by the StepOnePlus ${ }^{\mathrm{TM}}$ Real-Time PCR System (Applied Biosystems Inc.) with the following thermal cycling parameters: Enzyme activation at $95^{\circ} \mathrm{C}$ for $10 \mathrm{~min}, 45$ cycles of denaturation at $95^{\circ} \mathrm{C}$ for $15 \mathrm{sec}$ and annealing/extension at $60^{\circ} \mathrm{C}$ for $60 \mathrm{sec}$. The PCR reaction for each miRNA-cDNA was run in triplicate, as well as a negative control without a template, which was conducted in parallel to assess the specificity of the PCR reaction.
Statistical analysis. All the qPCR data were analyzed using the Relative Expression Software Tool V 2.0.13 (REST 2009; Qiagen). Mann-Whitney U tests and boxplots diagrams were generated using SPSS 20 (IBM, Armonk, NY, USA). P<0.05 was considered to indicate a statistically significant difference.

\section{Results}

miRNA analysis. RT-qPCR was performed for 4 miRNAs (hsa-let-7d, hsa-miR-98, hsa-miR-125a-5p and hsa-miR-218) in 13 JAs and 3 inferior nasal turbiantes. For all the 4 tested miRNAs, the expression level was found to be lower in JAs compared to nasal turbinates. However, the 2 miRNAs hsa-let-7d $(\mathrm{P}=0.158)$ and hsa-miR-98 $(\mathrm{P}=0.069)$ showed no statistically significant difference in expression between angiofibroma and inferior turbinate tissue, but a statistically significant lower expression was observed for hsa-miR-125a-5p $(\mathrm{P}=0.037)$ and for hsa-miR-218 $(\mathrm{P}=0.009)$ in JAs (Fig. 1).

\section{Discussion}

To the best of our knowledge, this is the first study to analyze miRNA in JA. A lower expression that was not statistically different was found for miRNA 98 and miRNA let-7d in JAs compared to the control tissue. Regarding the cellular heterogeneity of JAs (7) and due to numerous other cells 
being present in JAs, the present study may have failed to detect a statistical difference due to dilution of the tumor cell miRNA by miRNAs from other cells. The downregulation of the miRNAs may be important only in the tumor cell of JAs that remain to be defined. In other tumor entities, the expression level of miRNA 98 appears to be controversial. In the small cell lung cancer and also the HNSCC cell lines, miRNA 98 has been reported to be upregulated $(8,9)$, whereas in nasopharyngeal carcinoma it was underexpressed in relapsed patient samples (10). Furthermore, low expression levels of miRNA let-7d in combination with a downregulation of miRNA 205 have been found in HNSCC tissue indicating them as prognostic markers (11). In cell lines derived from oral cancer, miRNA let-7d overexpression reversed epithelial-mesenchymal transition, blocked migratory/invasive abilities and increased chemosensitivity (12). Regarding the suggested role of mesenchymal-epithelial transition, downregulation of miRNA let-7d correlates with the assumption of reversed epithelial-mesenchymal transition in the case of miRNA let-7d overexpression.

Notably, a tumor suppressive effect of miRNA 125a-5p has previously been described in gastric, breast and lung cancers (13-15). In addition, miRNA 125a-5p has been proposed as an independent prognostic marker in gastric cancer (16). miRNA $125 \mathrm{a}-5 \mathrm{p}$ has a critical role in inhibiting tumor migration and invasion in lung cancer (17). Gain-of-function experiments in lung cancer cell lines have shown that miRNA $125 \mathrm{a}-5 \mathrm{p}$ suppressed proliferation and induced apoptosis (15). In HNSCC, miRNA 125a-5p did not change (18) or was reduced regarding human papillomavirus (HPV)-positive tumors (19). In the present study, JA is shown to be one of numerous neoplasms that exhibit downregulated miRNA $125 \mathrm{a}-5 \mathrm{p}$.

Similar to the aforementioned studies, reduced miRNA 218 was observed in cervical squamous cell carcinomas (20). Notably, cervical intraepithelial neoplasia and cervical carcinoma cells with high-risk HPV infection compared to intermediate- or low-risk HPV infections also showed reduced miRNA 218 expression $(21,22)$. Based on the current knowledge of other tumors, the downregulation of miRNA 125a-5p and miRNA 218 supposedly increases proliferation by loss of the tumor suppressive activity in JAs.

Furthermore, the effect of miRNA 218 on the Wnt-signaling pathway is noteworthy, particularly in JA. GSK-3 $\beta$ usually leads to a complex of axin and adenomatous polyposis coli, which results in destabilization and degradation of $\beta$-catenin. In this context, miRNA 218 can induce, via inhibition of Akt, the inhibition of GSK-3 $\beta$. This effect results in stabilization and further translocation of $\beta$-catenin from the cytoplasm to the nucleus leading to specific gene activations $(6,23,24)$. As the frequently observed $\beta$-catenin mutations in JAs have been previously indicated to result in nuclear accumulation of stabilized $\beta$-catenin, the present finding of miRNA 218 downregulation represents a further pathway leading to nuclear accumulation of $\beta$-catenin in JAs and also in other tumor entities.

However, focus on the analysis of miRNA 218 in carcinomas is of interest in JAs, and the possible role of miRNA in development also requires investigating. JAs have been suggested to present vascular malformations (25) that arise from remnants of the first branchial arch artery (26). Currently, the detection of laminin $\alpha 2$, expression patterns of collagen I and collagen VI, as well as detection of teashirt zinc finger homeobox 1 in JAs support the definition of JAs as a vascular malformation $(27,28)$. Regulation of vascular patterning is attributed to miRNA 218 by modulation of Slit-Robo signaling. Knock-down of miRNA 218 was found to result in abnormal endothelial cell migration and a reduced complexity of the retinal vasculature (29).

In conclusion, to the best of our knowledge this is the first study to analyze miRNA expression in JAs with regards to observing deregulation of miRNAs. Statistically significant downregulation of miRNA $125 \mathrm{a}-5 \mathrm{p}$ is believed to stimulate miRNA tumor growth by the loss of this tumor suppressor. The downregulation of miRNA 218 and its effect on $\beta$-catenin is a novel finding that emphasizes the significance of $\beta$-catenin in tumor biology.

\section{Acknowledgements}

The authors would like to thank Mrs. Ulrike Bechtel and Dr Joana Heinzelmann for their expert technical assistance and helpful discussions.

\section{References}

1. Schick B and Kahle G: Radiological findings in angiofibroma. Acta Radiol 41: 585-593, 2000

2. Banno K, Iida M, Yanokura M, Kisu I, Iwata T, Tominaga E, Tanaka K and Aoki D: MicroRNA in cervical cancer: OncomiRs and tumor suppressor miRs in diagnosis and treatment. ScientificWorldJournal 2014: 178075, 2014.

3. Janiszewska J, Szaumkessel M and Szyfter K: microRNAs are important players in head and neck carcinoma: a review. Crit Rev Oncol Hematol 88: 716-728, 2013.

4. Zhang XH, Zhang YN and Liu Z: MicroRNA in chronic rhinosinusitis and allergic rhinitis. Curr Allergy Asthma Rep 14: 415, 2014.

5. Abraham SC, Montgomery EA, Giardiello FM and Wu TT: Frequent beta-catenin mutations in juvenile nasopharyngeal angiofibromas. Am J Pathol 158: 1073-1078, 2001.

6. Uesugi A, Kozaki K, Tsuruta T, Furuta M, Morita K, Imoto I, Omura $\mathrm{K}$ and Inazawa J: The tumor suppressive microRNA miR-218 targets the mTOR component Rictor and inhibits AKT phosphorylation in oral cancer. Cancer Res 71: 5765-5778, 2011.

7. Wendler O, Dlugaiczyk J, Birk S and Schick B: Anti-proliferative effect of glucocorticoids on mesenchymal cells in juvenile angiofibromas. Head Neck 34: 1615-1621, 2012.

8. Du L, Schageman JJ, Subauste MC, Saber B, Hammond SM, Prudkin L, Wistuba II,Ji L, Roth JA, Minna JD and Pertsemlidis A: miR-93, miR-98, and miR-197 regulate expression of tumor suppressor gene FUS1. Mol Cancer Res 7: 1234-1243, 2009.

9. Tran N, McLean T, Zhang X, Zhao CJ, Thomson JM, O'Brien C and Rose B: MicroRNA expression profiles in head and neck cancer cell lines. Biochem Biophys Res Commun 358: 12-17, 2007.

10. Alajez NM, Shi W, Hui AB, Bruce J, Lenarduzzi M, Ito E, Yue S, O'Sullivan B and Liu FF: Enhancer of Zeste homolog 2 (EZH2) is overexpressed in recurrent nasopharyngeal carcinoma and is regulated by miR-26a, miR-101, and miR-98. Cell Death Dis 1: e85, 2010

11. Childs G, Fazzari M, Kung G, Kawachi N, Brandwein-Gensler M, McLemore M, Chen Q, Burk RD, Smith RV, Prystowsky MB, et al: Low-level expression of microRNAs let-7d and miR-205 are prognostic markers of head and neck squamous cell carcinoma. Am J Pathol 174: 736-745, 2009.

12. Chang CJ, Hsu CC, Chang CH, Tsai LL, Chang YC, Lu SW Yu CH, Huang HS, Wang JJ, Tsai CH, et al: Let-7d functions as novel regulator of epithelial-mesenchymal transition and chemoresistant property in oral cancer. Oncol Rep 26: 1003-1010, 2011.

13. Hashiguchi Y, Nishida N, Mimori K, Sudo T, Tanaka F, Shibata K, Ishii H, Mochizuki H, Hase K, Doki Y and Mori M: Down-regulation of miR-125a-3p in human gastric cancer and its clinicopathological significance. Int J Oncol 40: 1477-1482, 2012. 
14. Guo X, Wu Y and Hartley RS: MicroRNA-125a represses cell growth by targeting HuR in breast cancer. RNA Biol 6: 575-583, 2009.

15. Jiang L, Huang Q, Chang J, Wang E and Qiu X: MicroRNA HSA-miR-125a-5p induces apoptosis by activating p53 in lung cancer cells. Exp Lung Res 37: 387-398, 2011.

16. Nishida N, Mimori K, Fabbri M, Yokobori T, Sudo T, Tanaka F, Shibata K, Ishii H, Doki Y and Mori M: MicroRNA-125a-5p is an independent prognostic factor in gastric cancer and inhibits the proliferation of human gastric cancer cells in combination with trastuzumab. Clin Cancer Res 17: 2725-2733, 2011.

17. Wang G, Mao W, Zheng S and Ye J: Epidermal growth factor receptor-regulated miR-125a-5p - a metastatic inhibitor of lung cancer. FEBS J 276: 5571-5578, 2009.

18. Odar K, Boštjančič E, Gale N, Glavač D and Zidar N: Differential expression of microRNAs miR-21, miR-31, miR-203, miR-125a-5p and $\mathrm{miR}-125 \mathrm{~b}$ and proteins PTEN and $\mathrm{p} 63$ in verrucous carcinoma of the head and neck. Histopathology 61: 257-265, 2012.

19. Lajer CB, Nielsen FC, Friis-Hansen L, Norrild B, Borup R, Garnæs E, Rossing M, Specht L, Therkildsen MH, Nauntofte B, et al: Different miRNA signatures of oral and pharyngeal squamous cell carcinomas: a prospective translational study. Br J Cancer 104: 830-840, 2011.

20. Yamamoto N, Kinoshita T, Nohata N, Itesako T, Yoshino H, Enokida H, Nakagawa M, Shozu M and Seki N: Tumor suppressive microRNA-218 inhibits cancer cell migration and invasion by targeting focal adhesion pathways in cervical squamous cell carcinoma. Int J Oncol 42: 1523-1532, 2013.

21. Li Y, Liu J, Yuan C, Cui B, Zou X and Qiao Y: High-risk human papillomavirus reduces the expression of microRNA-218 in women with cervical intraepithelial neoplasia. J Int Med Res 38: 1730-1736, 2010.
22. Martinez I, Gardiner AS, Board KF, Monzon FA, Edwards RP and Khan SA: Human papillomavirus type 16 reduces the expression of microRNA-218 in cervical carcinoma cells. Oncogene 27: 2575-2582, 2008.

23. Katoh M and Katoh M: Cross-talk of WNT and FGF signaling pathways at GSK3beta to regulate beta-catenin and SNAIL signaling cascades. Cancer Biol Ther 5: 1059-1064, 2006.

24. Alqurashi N, Hashimi SM and Wei MQ: Chemical inhibitors and microRNAs (miRNA) targeting the mammalian target of rapamycin (mTOR) pathway: potential for novel anticancer therapeutics. Int J Mol Sci 14: 3874-3900, 2013.

25. Beham A, Beham-Schmid C, Regauer S, Auböck L and Stammberger H: Nasopharyngeal angiofibroma: true neoplasm or vascular malformation? Adv Anat Pathol 7: 36-46, 2000.

26. Schick B, Plinkert PK and Prescher A: Aetiology of angiofibromas: reflection on their specific vascular component. Laryngorhinootologie 81: 280-284, 2002 (In German).

27. Schick B, Wemmert S, Willnecker V, Dlugaiczyk J, Nicolai P, Siwiec H, Thile CT, Rauch A and Wendler O: Genome-wide copy number profiling using a 100K SNP array reveals novel disease-related genes BORIS and TSHZ1 in juvenile angiofibroma. Int J Oncol 39: 1143-1151, 2011.

28. Starlinger V, Wendler O, Gramann M and Schick B: Laminin expression in juvenile angiofibromas indicates vessel's early developmental stage. Acta Otolaryngol 127: 1310-1315, 2007.

29. Small EM, Sutherland LB, Rajagopalan KN, Wang S and Olson EN: MicroRNA-218 regulates vascular patterning by modulation of Slit-Robo signaling. Circ Res 107: 1336-1344, 2010. 